\title{
Twenty-year outcomes of coronary artery bypass grafting utilizing 3 in situ arterial grafts
}

\author{
Giuseppe Tavilla, MD, PhD, ${ }^{a}$ Eline F. Bruggemans, MSc, ${ }^{a}$ and Hein Putter, $\mathrm{PhD}^{\mathrm{b}}$
}

\section{ABSTRACT}

Objective: The added value of total arterial revascularization in coronary artery bypass grafting becomes particularly apparent when evaluating long-term results. We previously reported on our 10-year outcomes of total arterial revascularization using bilateral internal thoracic and gastroepiploic arteries as in situ grafts in patients with 3-vessel disease. This study aimed to increase the follow-up period to 20 years.

Methods: We updated clinical outcomes of 201 patients operated on between 1992 and 2002. At that time, the technique was primarily performed in patients with a longer life expectancy. Primary end points were overall survival and freedom from the composite of major adverse cardiac events. Secondary end points were the separate cardiac events.

Results: Extended follow-up included all patients. The median follow-up time was 19.2 years (interquartile range, 16.2-20.0). The respective 15- and 20-year Kaplan-Meier estimated survival probabilities were $73.9 \%$ (95\% confidence interval [CI], 67.2\%-79.5\%) and 63.5\% (95\% CI, 55.7\%-70.4\%) for overall survival and $57.9 \%(95 \%$ CI, $50.7 \%-64.5 \%)$ and $47.9 \% \quad(95 \%$ CI, $40.1 \%-55.3 \%$ ) for freedom from major adverse cardiac events. The respective estimated cumulative incidences at 15 and 20 years were $7.0 \%(95 \% \mathrm{CI}$, $3.5 \%-10.6 \%)$ and $7.8 \%(95 \% \mathrm{CI}, 4.0 \%-11.6 \%)$ for myocardial infarction, $8.6 \% \quad(95 \%$ CI, $4.7 \%-12.5 \%)$ and $9.3 \% \quad(95 \%$ CI, $5.2 \%-13.3 \%)$ for percutaneous reintervention, $7.0 \%(95 \% \mathrm{CI}, 3.5 \%-10.5 \%)$ and $7.0 \%(95 \%$ CI, 3.5\%-10.5\%) for reoperation, $8.6 \%$ (95\% CI, $4.7 \%-12.6 \%)$ and $12.9 \%$ (95\% CI, 7.6\%-18.2\%) for cardiac death, and 10.8\% (95\% CI, 6.5\%-15.2\%) and $15.2 \%$ (95\% CI, 9.8\%-20.6\%) for death from other causes.

Conclusions: The use of in situ bilateral internal thoracic and gastroepiploic arteries provides outstanding 15- and 20-year survival and cardiac event-free survival probabilities. Further studies are needed in older patients with more severe comorbidities. Nevertheless, the results from this and scarce other studies on 15- to 20-year outcomes of total arterial revascularization suggest that cardiac surgeons should embrace the application of total arterial grafting to further reduce the risks of long-term cardiac events, especially during the second decade after surgery. (J Thorac Cardiovasc Surg 2019;157:2228-36)

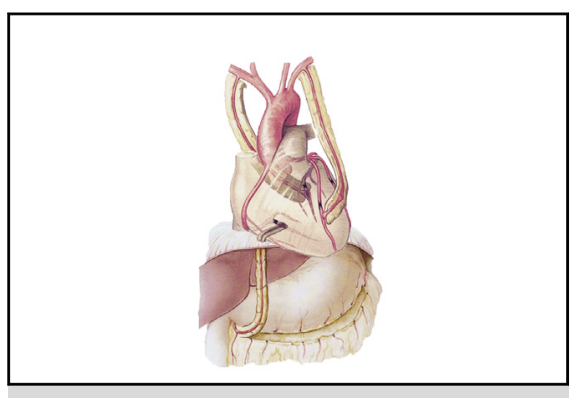

Total arterial revascularization with 3 in situ grafts.

\section{Central Message}

The use of in situ bilateral internal thoracic and gastroepiploic arteries reduces the risks of long-term cardiac events, especially during the second decade after coronary artery bypass grafting.

\section{Perspective}

There are scarce published data on very long-term outcomes (15 years or longer) after coronary artery bypass grafting with at least 2 arterial grafts. The results from this study and similar studies with sufficient follow-up time suggest that cardiac surgeons should embrace the application of total arterial grafting to further reduce the risks of long-term cardiac events.

See Commentaries on pages 2237 and 2240.
In evaluating outcomes of coronary artery bypass grafting (CABG), multiple studies have demonstrated the

From the Departments of ${ }^{\mathrm{a} C}$ Cardiothoracic Surgery and ${ }^{\mathrm{b}}$ Biomedical Data Sciences, Leiden University Medical Center, Leiden, The Netherlands.

Received for publication July 16, 2018; revisions received Nov 28, 2018; accepted for publication Dec 3, 2018; available ahead of print Feb 15, 2019.

Address for reprints: Giuseppe Tavilla, MD, PhD, Department of Cardiothoracic Surgery, Leiden University Medical Center, PO Box 9600, 2300 RC Leiden, The Netherlands (E-mail: G.Tavilla@lumc.nl).

0022-5223/\$36.00

Copyright (c) 2018 by The American Association for Thoracic Surgery

https://doi.org/10.1016/j.jtcvs.2018.12.013 long-term survival benefit of the use of bilateral internal thoracic artery (BITA) grafts over that of a single internal thoracic artery (SITA) supplemented with saphenous vein grafts (SVGs). ${ }^{1-7}$ Moreover, the exclusive use of arterial

Scanning this $\mathrm{QR}$ code will take you to the article title page to access supplementary information. 


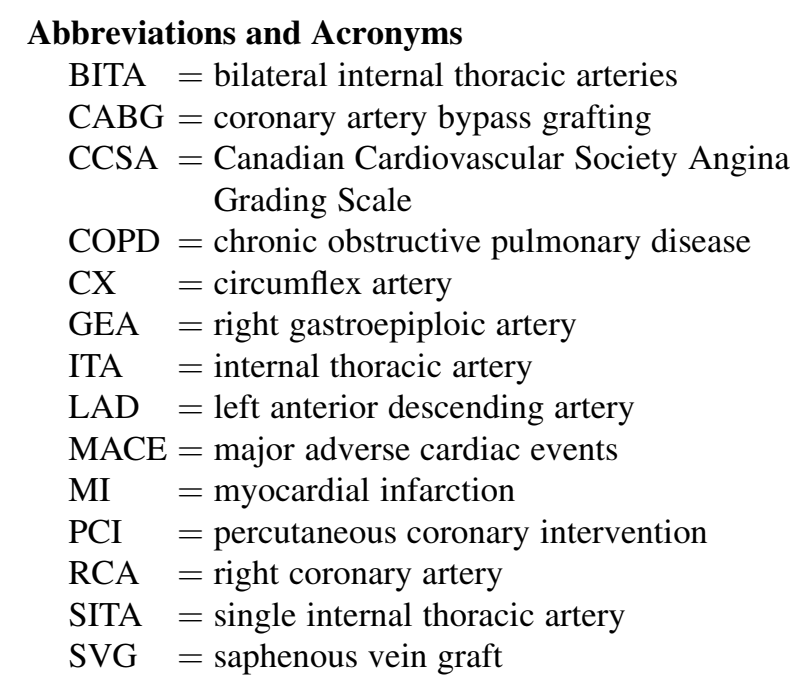

grafts seems to confer an incremental survival benefit relative to BITA grafting with $\mathrm{SVG}^{8,9}$ To achieve total arterial revascularization in patients with 3 -vessel disease, the right gastroepiploic artery (GEA) graft may be a good option to supplement BITA grafts. ${ }^{10,11}$ This third arterial conduit has potential advantages over the BITA Y-graft strategy or the use of the radial artery because it is a third in situ graft.

In 2004, we reported the short- and long-term results of total arterial revascularization with BITA and GEA grafts in patients with 3-vessel disease and showed an excellent 10 -year survival probability of $87 \% .{ }^{12}$ However, although the survival and cardiac event-free survival benefits seemed undeniable compared with BITA grafting supplemented with SVG, the potential very long-term advantages (after 15 years of follow-up) of this revascularization strategy are not yet well established. The aim of the present study was to report the extended long-term follow-up data of the previous patient cohort.

\section{MATERIAL AND METHODS \\ Study Design}

The current study is an analysis based on the extended follow-up of patients included in a previous study on BITA plus GEA grafting to achieve total arterial revascularization. ${ }^{12}$ The extended follow-up study was approved by the ethics committees of the involved hospitals.

\section{Patient Population}

Between November 1992 and May 2002, 201 patients with 3-vessel disease underwent total arterial revascularization with the use of BITA and GEA as in situ grafts by 1 surgeon (GT) in 3 Dutch hospitals (Catharina Hospital Eindhoven, St Antonius Hospital Nieuwegein, and Leiden University Medical Center).

This revascularization strategy was preferentially used in patients with a life expectancy of more than 10 years. Contraindications were severe chronic obstructive pulmonary disease (COPD), severe or poorly controlled insulin-dependent diabetes mellitus, cardiogenic shock, extreme chest deformities, and previous gastrointestinal resection. Previous cholecystectomy was not a contraindication.

\section{Surgical Technique}

The surgical technique regarding the harvesting, routing, and treatment of the BITA and GEA grafts has been described previously. ${ }^{13}$ All patients were operated on with the use of extracorporeal circulation. Two graft configurations were used. In 157 patients (78\%), the left internal thoracic artery (ITA) was placed to the left anterior descending artery (LAD) system, the right ITA through the transvers sinus to the circumflex artery (CX) system and the GEA to the right coronary artery (RCA) system (Figure 1, A) (Video 1). In 44 patients $(22 \%)$, the right ITA was placed to the LAD system in front of the aorta, the left ITA to the CX system and the GEA to the RCA system (Figure $1, B$ ). An endarterectomy was performed in 13 patients $(6 \%)$.

All patients received lifelong antiplatelet therapy postoperatively. Postoperative statin prescription in our patient cohort became common practice over the years.

\section{Follow-up}

Follow-up information on major adverse cardiac events (MACE) was obtained by telephone interviews conducted by GT with the patients, family members, or their referring cardiologists when the patient was unreachable. The common closing date for follow-up was March 1, 2015. All outcomes of interest were confirmed by source documentation collected from referring cardiologists or general practitioners.

\section{End Points and Definitions}

The primary outcomes were overall survival and freedom from the composite end point of MACE, defined as the first occurrence of myocardial infarction (MI), percutaneous coronary intervention (PCI), re-CABG, cardiac death, or death from other causes. Secondary outcomes were the separate clinical events MI, PCI, re-CABG, cardiac death, and death from other causes. Cardiac death was defined as death due to acute cardiac arrest, MI, sudden death, progressive congestive heart failure, and unknown causes. Deaths occurring before hospital discharge or within 30 days were considered cardiac deaths. MI was defined by a rise in creatine kinase-MB isoform by 3 times the upper limit of normal, enzymatic elevation of serum glutamic oxaloacetic transaminase $\geq 100$, and/or troponin $\mathrm{T}>1 \mu \mathrm{g} / \mathrm{L}$ and development of new Q-wave associated with creatine kinase-MB elevation consistent with myocardial necrosis.

\section{Statistical Analysis}

Continuous data are presented as mean \pm standard deviation or as median (interquartile range [IQR]), as appropriate. Categorical data are presented as number and percentage. Median and IQR of follow-up time were calculated using the reverse Kaplan-Meier method. ${ }^{14}$ Overall survival and event-free survival probabilities were estimated using the Kaplan-Meier method and reported as percentage $(95 \%$ confidence interval $[\mathrm{CI}])$. For first event analysis of the secondary end points, the components of MACE, cumulative incidence probabilities were estimated accounting for competing risks. ${ }^{15}$ For each component of MACE, all other components of MACE were used as competing risks. Multivariable Cox regression analysis with forward stepwise selection was used to examine predictors of the primary end points. The predictor variables considered were age, gender, hypertension, hyperlipidemia, diabetes mellitus, peripheral vascular disease, COPD, smoking history, obesity (body mass index $>25$ ), history of $\mathrm{MI}$, prior CABG, unstable angina (Canadian Cardiovascular Society Angina Grading Scale [CCSA] class IV), left ventricular dysfunction (ejection fraction $<50 \%$ ), and left main stenosis. Probabilities used for entrance and removal in the stepwise method were 0.05 and 0.10 , respectively. All analyses included in-hospital outcomes. 


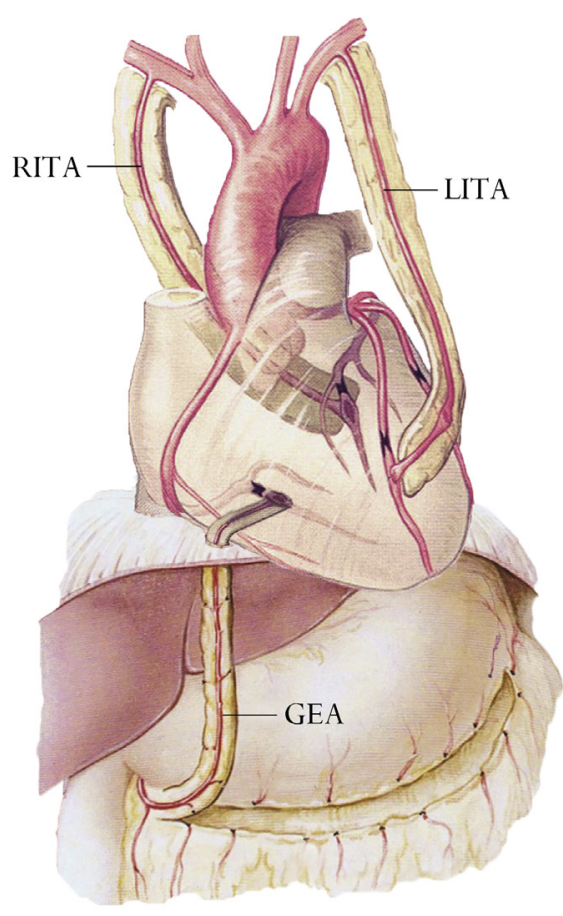

A

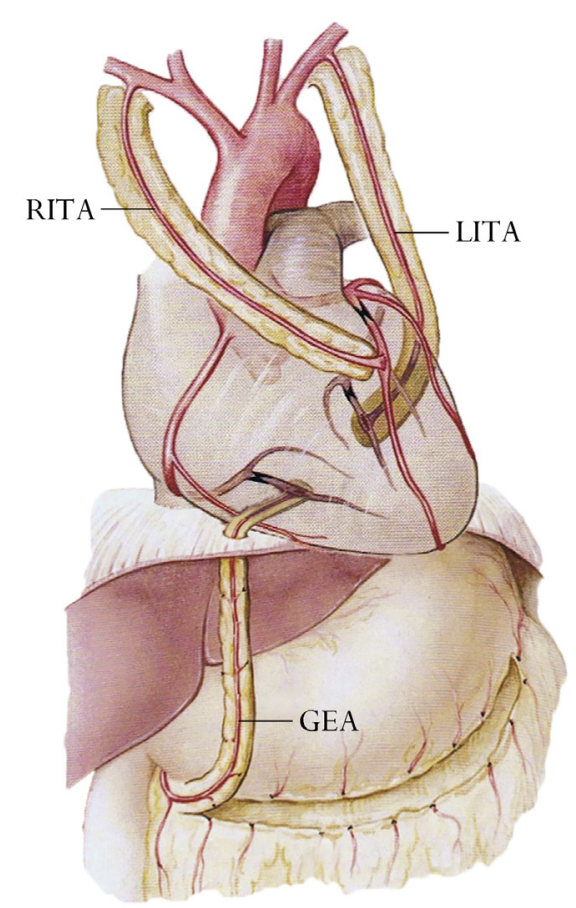

B

FIGURE 1. Total arterial revascularization with 3 in situ grafts. A, Left internal thoracic artery (LITA) to the left anterior descending artery (LAD) system, right internal thoracic artery (RITA) to the circumflex artery (CX) system, and right gastroepiploic artery (GEA) to the right coronary artery (RCA) system. B, RITA to the LAD system, LITA to the CX system, and GEA to the RCA system.

Survival and competing risks analyses were performed using the prodlim package version 1.6.1 for $\mathrm{R}$ version 3.4.2 (R Foundation for Statistical Computing, Vienna, Austria). All other statistical analyses were performed using IBM-SPSS Statistics for Windows version 23.0 (IBM-SPSS Inc, Armonk, NY).

\section{RESULTS}

\section{Characteristics of the Study Population and Follow-up}

Patient characteristics of the study cohort are summarized in Table 1. Details on the site of the anastomoses and in-hospital outcomes are described in our previous report. ${ }^{12}$ No patient was lost to follow-up. Median follow-up time was 19.2 years (IQR, 16.2-20.0 years). The percentages of patients with more than 15 and 20 years of follow-up were $82.1 \%$ and $26.6 \%$, respectively.

\section{Primary Outcomes}

During follow-up there were 59 deaths, 27 from a cardiac cause. Noncardiac death included malignancy in 19 patients, pulmonary failure in 6 patients, and other causes in 7 patients. For the total study cohort $(\mathrm{N}=201)$, estimated overall survival probabilities at 10,15 , and 20 years were $84.0 \% \quad(95 \% \quad$ CI, $78.1 \%-88.4 \%), \quad 73.9 \% \quad(95 \% \quad$ CI, 67.2\%-79.5\%), and $63.5 \%$ (95\% CI, $55.7 \%-70.4 \%)$, respectively (Figure 2, A) (Table 2) and estimated freedom from MACE probabilities at 10,15 , and 20 years were
$69.4 \% \quad(95 \% \quad$ CI, $\quad 62.5 \%-75.3 \%), \quad 57.9 \% \quad(95 \% \quad$ CI, $50.7 \%-64.5 \%$ ), and $47.9 \%$ (95\% CI, $40.1 \%-55.3 \%)$, respectively (Figure 2, $B$ ).

Multivariable Cox regression analysis in the total study cohort revealed 5 independent predictors of all-cause death: age (hazard ratio [HR], 1.07; 95\% CI, 1.02-1.11; $P=.002$ ), obesity (HR, 2.08; 95\% CI, 1.20-3.59; $P=.009$ ), smoking history (HR, 2.08; 95\% CI, 1.26-3.44; $P=.004$ ), COPD (HR, 2.26; 95\% CI, 1.08-4.77; $P=.032$ ), and CCSA class IV (HR, 1.92; 95\% CI, 1.11-3.33; $P=.021$ ), and revealed 2 independent predictors of MACE: age (HR, $1.03 ; 95 \% \mathrm{CI}$, $1.00-1.07 ; P=.031)$ and CCSA class IV (HR, 1.90; 95\% CI, 1.23-2.94; $P=.004)$.

\section{Secondary Outcomes}

Ten patients experienced MI during follow-up. The estimated cumulative incidences for MI in the total study cohort at 10,15 , and 20 years were $6.5 \%, 7.0 \%$, and $7.8 \%$, respectively (Figure 3, A) (Table 2). Twenty-seven patients underwent PCI after hospital discharge. In 25 patients, a native coronary artery was treated (6 previously ungrafted vessels). PCI concerned a vessel of the RCA system in 13 patients, the CX system in 7 patients, and the LAD system in 5 patients. In 2 patients, a PCI of a left ITA graft was performed. The estimated cumulative incidences for PCI in the total study cohort at 10, 15, and 


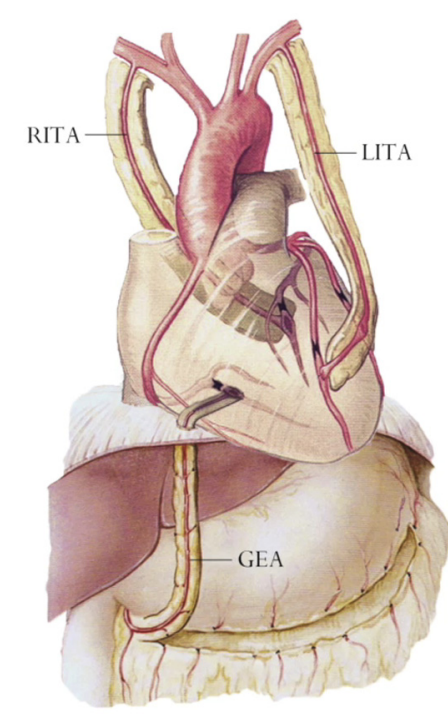

VIDEO 1. Surgical technique of total arterial revascularization utilizing 3 in situ grafts. In the video, the off-pump technique is used because nowadays this is the preferred technique of the first author for this type of revascularization. Video available at: https://www.jtcvs.org/article/ S0022-5223(18)33450-0/fulltext.

20 years were $5.5 \%, 8.6 \%$, and $9.3 \%$, respectively (Figure 3, B). Four patients underwent re-CABG after hospital discharge. Two patients received an SVG on the LAD with the off-pump technique at, respectively, 9 and 14 years after the index surgery. One patient received an SVG on the RCA in conjunction with an aortic valve replacement 8 years after surgery. One patient received an SVG on the LAD and an SVG on the RCA together with mitral and tricuspid valve repair at 11 years after surgery. The estimated cumulative incidences for re-CABG in the total study cohort at 10,15 , and 20 years were $6.5 \%$, $7.0 \%$, and $7.0 \%$, respectively (Figure 3,C). The estimated cumulative incidences for cardiac death in the total study cohort at 10,15 , and 20 years were $6.0 \%, 8.6 \%$, and $12.9 \%$, respectively (Figure 3, D), and for death from other causes were $6.0 \%, 10.8 \%$, and $15.2 \%$, respectively (Figure 3, E).

\section{DISCUSSION}

The best choice of conduits in CABG becomes especially apparent when evaluating long-term results. This study reports on the largest patient cohort with 3-vessel disease undergoing total arterial revascularization using exclusively in situ BITA and GEA grafts and among the longest follow-up periods (median, 19.2 years [IQR, 16.2-20.0 years]) to date. Moreover, it is among the few studies that reports on the long-term probabilities of freedom from MACE in total arterial revascularization. Although all-cause death is an important end point in studies investigating the clinical effect of total arterial
TABLE 1. Baseline patient characteristics $(N=201)$

\begin{tabular}{lc}
\hline \multicolumn{1}{c}{ Variable } & Value \\
\hline Age (y) & $53.2 \pm 6.9$ \\
Female sex & $9(4.5)$ \\
Body mass index $>25$ & $45(22.4)$ \\
Medical history & \\
$\quad$ Previous myocardial infarction & $115(57.2)$ \\
Hyperlipidemia & $113(56.2)$ \\
Hypertension & $85(42.3)$ \\
Diabetes & $21(10.6)$ \\
Chronic obstructive pulmonary disease & $15(7.5)$ \\
Peripheral vessel disease & $11(5.5)$ \\
Smoking history & $88(43.8)$ \\
Previous CABG & $10(5.0)$ \\
Canadian Cardiovascular Society Angina Grading Scale class & \\
III & $116(57.7)$ \\
IV & $45(22.4)$ \\
Left ventricle ejection fraction & \\
Moderate & $50(24.9)$ \\
Poor & $13(6.5)$ \\
\hline Left main stenosis & $35(17.4)$ \\
Emergency surgery & $27(13.4)$ \\
\hline Values are presented as mean \pm standard deviation or n (\%). CABG, Coronary artery \\
bypass grafting.
\end{tabular}

revascularization, MACE probabilities may add decisive information in the search of the best choice of conduits in patients with multivessel disease.

The estimated overall survival probability at 20 years after surgery in our patient cohort was $63.5 \%(95 \% \mathrm{CI}$, $55.7 \%-70.4 \%$ ). This result confirms the excellent very long-term survival probability reported in the only other study in the literature addressing the 20-year outcomes of CABG with BITA plus GEA grafting. Glineur and colleagues ${ }^{16}$ compared patients who received the GEA as a third conduit in addition to BITA grafting with those who received BITA grafting with SVG. They found that the survival probability at 20 years after surgery was $68.9 \%$ for BITA/GEA grafting versus $50.3 \%$ for BITA/SVG grafting. The 20-year survival benefit of using BITA/SVG compared with SITA/SVG has previously been demonstrated by Lytle and colleagues. ${ }^{17}$ They showed that the benefit of BITA grafting increased through the 20 postoperative years and that improved survival compared with SITA grafting became more evident during the second postoperative decade.

There are scarce published data regarding very long-term survival after CABG with at least 2 arterial grafts. We identified only 7 studies reporting on survival probabilities at 15 years or more of follow-up ${ }^{6,16-21}$ (Table 3). As can be deduced from Table 3, the survival benefit of total arterial revascularization compared with BITA/SVG grafting seems to increase with extension of the follow-up period, like the 


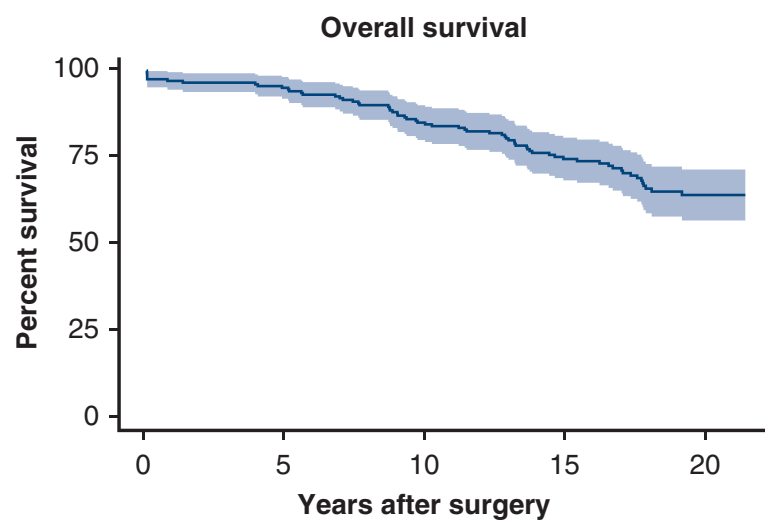

No. at Risk: 201
166

122
34

A intervals.

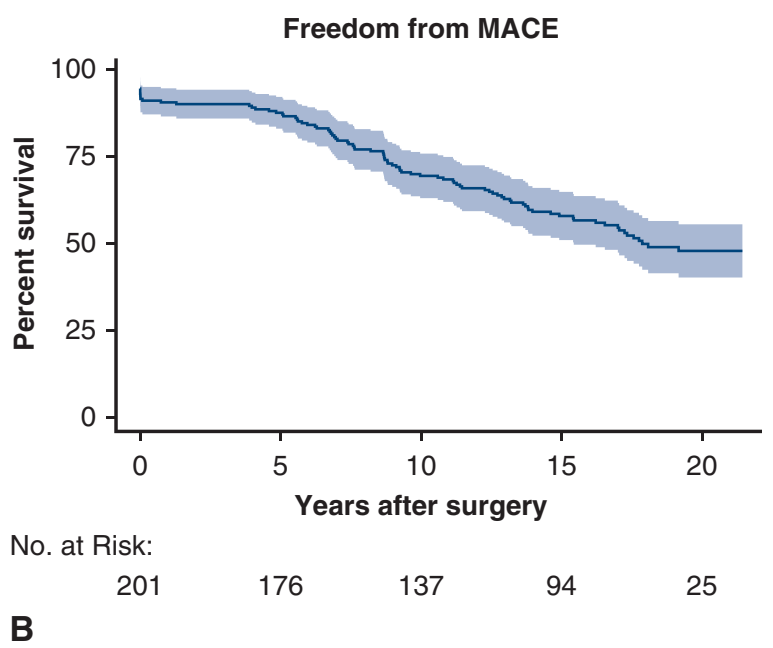

divergence with time of the survival probabilities for BITA/SVG versus SITA/SVG grafting. ${ }^{17}$ The graft configuration was not homogeneous in the majority of the reported patient cohorts. In a cohort of 93 patients with BITA/GEA grafting, 20 patients also received an SVG. ${ }^{16}$ In another group of patients with total arterial revascularization, the grafts used were not specified. ${ }^{18}$ Four studies reported on combined data for patients who underwent BITA grafting with and without SVG. ${ }^{6,16,17,21}$ Studies on more homogeneous patient groups are needed for definite conclusions.

The 20-year estimated freedom from MACE probability in our series was $47.9 \%$ (95\% CI, $40.1 \%-55.3 \%)$. Only 2 studies included in Table 3 included information on the incidence of MACE in their reports. ${ }^{18,21}$ Garatti and colleagues $^{18}$ reported a 15 -year freedom from MACE probability of $58 \%$ in patients who underwent total arterial revascularization. This is similar to our 15 -year probability, although Garatti and colleagues ${ }^{18}$ did not include re-CABG in their composite end point of MACE. Parsa and colleagues $^{21}$ found $35 \%$ and $20 \%$ event-free survival probabilities (as estimated from the unadjusted Kaplan-Meier curve) for the MACE composite outcome at 15 and 20 years after surgery, respectively, in patients undergoing BITA grafting with or without SVG. These are much worse numbers than those found in both the cohorts with total arterial revascularization. In their analysis, however, patients with multiple ITA grafts were defined only by the number of distal ITA anastomoses. Clinical outcomes of sequential multiple ITA grafting to the same coronary system may resemble those of SITA grafting. Consequently, the beneficial effects of BITA grafting might have been weakened in their study.

The present analysis included in-hospital mortality and MACE. When evaluating the very long-term outcomes of the current technique, it is also worthwhile to reflect on the results after hospitalization, especially on the probabilities of repeat revascularization. In our series,

TABLE 2. Clinical outcomes

\begin{tabular}{|c|c|c|c|c|}
\hline Outcome & $5 y$ & $10 y$ & $15 y$ & $20 y$ \\
\hline \multicolumn{5}{|l|}{ Survival probability } \\
\hline No. at risk & 190 & 166 & 122 & 34 \\
\hline Overall survival & $94.5(90.3-96.9)$ & $84.0(78.1-88.4)$ & $73.9(67.2-79.5)$ & $63.5(55.7-70.4)$ \\
\hline \multicolumn{5}{|l|}{ Cumulative incidence } \\
\hline No. at risk & 176 & 137 & 94 & 25 \\
\hline MACE & $12.4(8.6-17.8)$ & $30.6(24.7-37.5)$ & $42.1(35.5-49.3)$ & $52.1(44.7-59.9)$ \\
\hline Myocardial infarction & $3.0(0.6-5.3)$ & $6.5(3.1-9.9)$ & $7.0(3.5-10.6)$ & $7.8(4.0-11.6)$ \\
\hline Percutaneous reintervention & $1.0(0.0-2.4)$ & $5.5(2.3-8.7)$ & $8.6(4.7-12.5)$ & $9.3(5.2-13.3)$ \\
\hline Reoperation & $5.5(2.3-8.6)$ & $6.5(3.1-9.9)$ & $7.0(3.5-10.5)$ & $7.0(3.5-10.5)$ \\
\hline Cardiac death & $1.5(0.0-3.2)$ & $6.0(2.7-9.4)$ & $8.6(4.7-12.6)$ & $12.9(7.6-18.2)$ \\
\hline Death from other causes & $1.5(0.0-3.2)$ & $6.0(2.7-9.3)$ & $10.8(6.5-15.2)$ & $15.2(9.8-20.6)$ \\
\hline
\end{tabular}

Values are presented as $\%$ ( $95 \%$ confidence interval). For the components of MACE, cumulative incidence probabilities were estimated accounting for competing risks. $M A C E$, Major adverse cardiac events. 


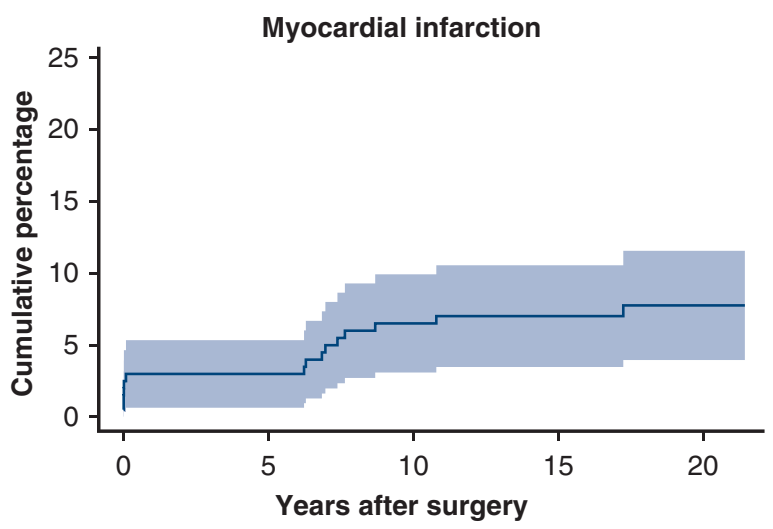

No. at Risk:

201

176

137

94

25

A

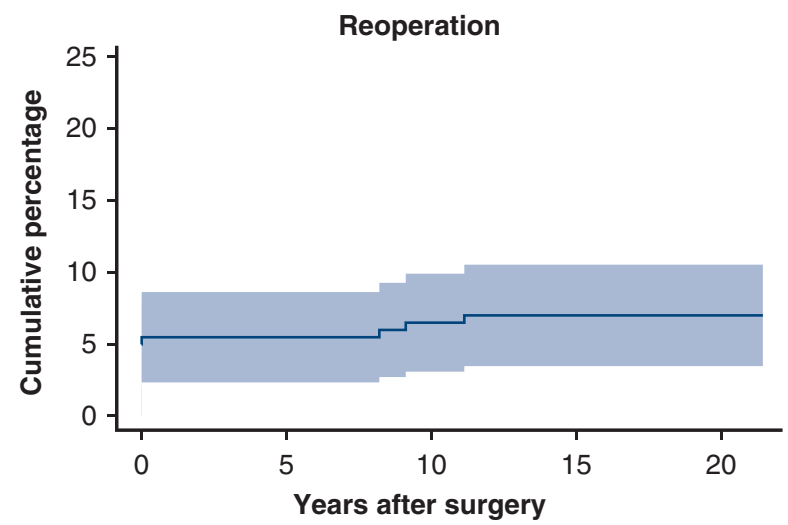

No. at Risk:

201

176

137

94

25

C

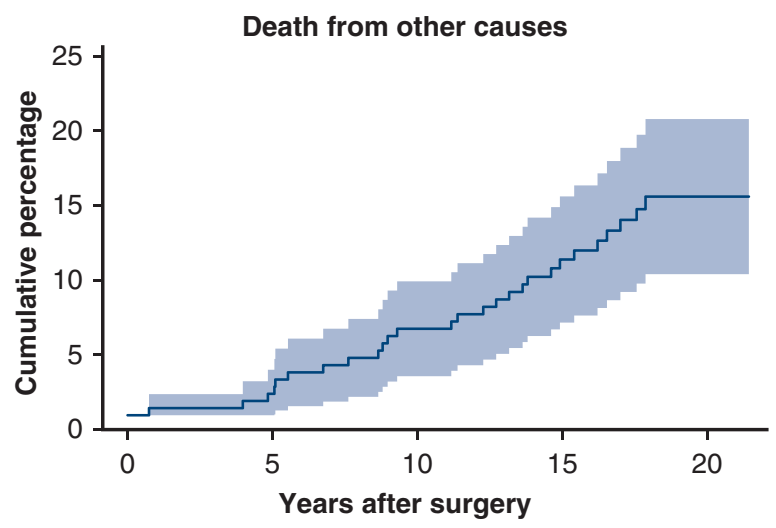

No. at Risk:
201
176
137
94
25

E

FIGURE 3. Cumulative incidence curves for the components of major adverse cardiac events. A, Myocardial infarction. B, Percutaneous reintervention. C, Reoperation. D, Cardiac death. E, Death from other causes. Shaded areas indicate $95 \%$ confidence intervals.

only 4 patients $(2.0 \%)$ required postdischarge re-CABG during a follow-up period of up to more than 21 years. Only 27 patients $(13.8 \%)$ underwent postdischarge PCI.

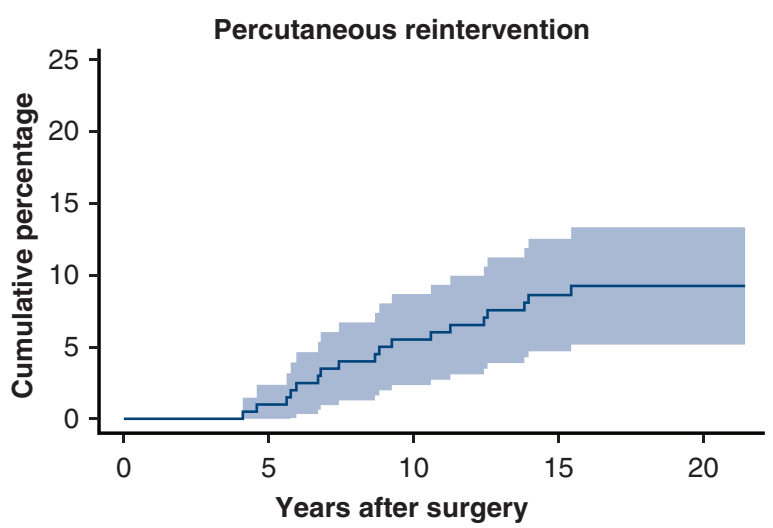

No. at Risk:

201

$176 \quad 137$

94

25

B

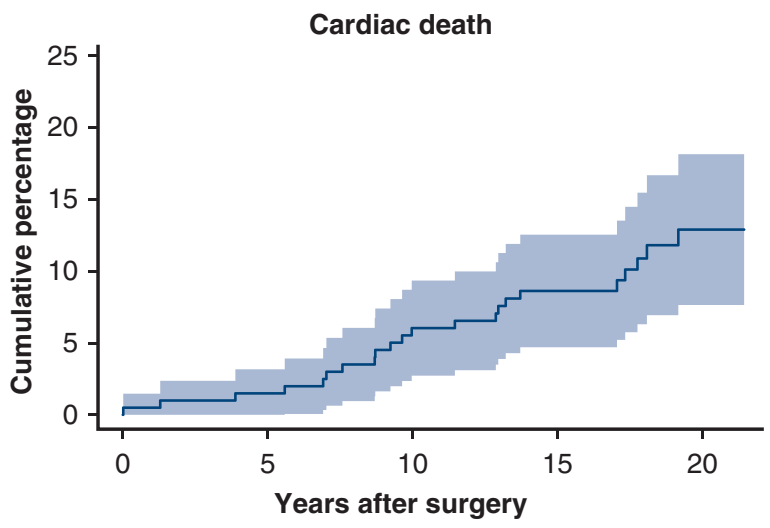

No. at Risk:

$\begin{array}{lllll}\text { D } & 201 & 176 & 137 & 94\end{array}$


TABLE 3. Long-term outcomes of coronary artery bypass grafting with at least 2 arterial grafts

\begin{tabular}{|c|c|c|c|c|c|c|c|c|c|c|c|}
\hline \multirow{2}{*}{$\begin{array}{c}\text { Surgical } \\
\text { technique }\end{array}$} & \multirow[b]{2}{*}{ Author(s) } & \multirow{2}{*}{$\begin{array}{l}\text { Type of } \\
\text { conduits }\end{array}$} & \multirow{2}{*}{$\begin{array}{c}\text { No. of } \\
\text { patients }\end{array}$} & \multicolumn{4}{|c|}{ Survival } & \multicolumn{4}{|c|}{ Freedom from MACE } \\
\hline & & & & $10 y$ & $15 y$ & $20 y$ & $25 y$ & $10 y$ & $15 y$ & $20 y$ & $25 y$ \\
\hline \multirow[t]{5}{*}{ TAR } & $\begin{array}{l}\text { Suma and } \\
\quad \text { colleagues }^{19}\end{array}$ & BITA/GEA & 165 & $\begin{array}{l}85.4 \\
(\mathrm{n}=99)\end{array}$ & $\begin{array}{l}81.4 \\
(\mathrm{n}=13)\end{array}$ & - & - & - & - & - & - \\
\hline & $\begin{array}{l}\text { Glineur and } \\
\text { colleagues }^{16}\end{array}$ & BITA/GEA & 93 & 98.9 & - & 68.9 & - & - & - & - & - \\
\hline & $\begin{array}{l}\text { Tavilla and } \\
\text { colleagues* }\end{array}$ & BITA/GEA & 201 & $\begin{array}{c}84 \\
(\mathrm{n}=166)\end{array}$ & $\begin{array}{c}73.9 \\
(\mathrm{n}=122)\end{array}$ & $\begin{array}{l}63.5 \\
(\mathrm{n}=34)\end{array}$ & - & $\begin{array}{c}69.4 \\
(\mathrm{n}=137)\end{array}$ & $\begin{array}{l}57.9 \\
(\mathrm{n}=94)\end{array}$ & $\begin{array}{l}47.9 \\
(n=25)\end{array}$ & - \\
\hline & $\begin{array}{l}\text { Shi and } \\
\text { colleagues }^{20}\end{array}$ & BITA/RA & 1037 & $\begin{array}{c}90 \\
(\mathrm{n}=629)\end{array}$ & $\begin{array}{c}82 \\
(\mathrm{n}=232)\end{array}$ & - & - & - & - & - & - \\
\hline & $\begin{array}{l}\text { Garatti and } \\
\text { colleagues }^{18}\end{array}$ & $\begin{array}{l}\text { Not } \\
\quad \text { specified }\end{array}$ & 209 & 91 & 82 & - & - & $77 \dagger$ & $58 \dagger$ & - & - \\
\hline \multirow[t]{5}{*}{$\begin{array}{l}\text { non- } \\
\text { TAR }\end{array}$} & $\begin{array}{l}\text { Lytle and } \\
\text { colleagues }^{17}\end{array}$ & BITA/SVG & 1152 & $\begin{array}{c}81 \\
(\mathrm{n}=933)\end{array}$ & $\begin{array}{c}67 \\
(\mathrm{n}=605)\end{array}$ & $\begin{array}{c}50 \\
(\mathrm{n}=34)\end{array}$ & - & - & - & - & - \\
\hline & $\begin{array}{c}\text { Kurlansky and } \\
\text { colleagues }^{6}\end{array}$ & BITA/SVG & 2215 & $\begin{array}{c}72 \ddagger \\
(\mathrm{n}=1577)\end{array}$ & 53.5 & $\begin{array}{c}39 \ddagger \\
(\mathrm{n}=131)\end{array}$ & 28.6 & - & - & - & - \\
\hline & $\begin{array}{l}\text { Glineur and } \\
\text { colleagues }^{16}\end{array}$ & BITA/SVG & 204 & 87.2 & - & 50.3 & - & - & - & - & - \\
\hline & $\begin{array}{l}\text { Shi and } \\
\text { colleagues }^{20}\end{array}$ & BITA/SVG & 460 & $\begin{array}{c}80 \\
(\mathrm{n}=336)\end{array}$ & $\begin{array}{c}67 \\
(\mathrm{n}=225)\end{array}$ & - & - & - & - & - & - \\
\hline & $\begin{array}{l}\text { Parsa and } \\
\text { colleagues }^{21}\end{array}$ & BITA/SVG & 728 & $70 \ddagger$ & $50 \ddagger$ & $33 \ddagger$ & $20 \ddagger$ & $\begin{array}{c}55 \ddagger \\
(\mathrm{n}=350)\end{array}$ & $\begin{array}{c}35 \ddagger \\
(\mathrm{n}=170)\end{array}$ & $\begin{array}{c}20 \ddagger \\
(\mathrm{n}=80)\end{array}$ & $\begin{array}{c}15 \ddagger \\
(\mathrm{n}=15)\end{array}$ \\
\hline
\end{tabular}

Values are presented as \% (No. at risk). MACE, Major adverse cardiac events; TAR, total arterial revascularization; BITA, bilateral internal thoracic arteries; GEA, right gastroepiploic artery; $S V G$, saphenous vein graft. *This study. $\dagger$ The composite end point of major adverse cardiac events did not include redo coronary artery bypass grafting.

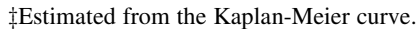

metabolically active grafts, produce vasoactive and endothelial progenitor substances that may slow the progression of native coronary artery disease. ${ }^{23,24}$ Of 27 patients requiring PCI, the native coronary artery was treated in 25 patients. In these 25 patients, the PCI concerned a vessel of the RCA system (the bypass target of the GEA graft) in 13 patients and the CX and LAD systems (targets of the BITA grafts) in 12 patients. Those numbers suggest that there are no functional differences between the use of the GEA compared with BITA.

The use of the GEA in addition to BITA grafts to achieve total arterial revascularization in 3-vessel disease has the potential advantage of using only in situ grafts. With this technique, 3 different sources supply blood to the myocardium. In contrast, with the BITA Y-graft strategy or the use of the radial artery, the blood supply of the myocardium is dependent on only 1 (1 ITA) or at most 2 sources (an ITA and/or the ascending aorta), respectively. In addition, the use of 3 in situ arterial grafts avoids the need of a Y-anastomosis or a proximal anastomosis on the ascending aorta that may create a potential procedural risk. The patency of the GEA graft is satisfactory. Suma and colleagues ${ }^{19}$ reported a patency of $87 \%$ in 124 patients with a mean follow-up time of 8.7 years (range, 5-17 years). Suzuki and colleagues ${ }^{25}$ demonstrated that the long-term patency for the skeletonized GEA is superior to that of the pedicled GEA and reported a cumulative patency probability for the skeletonized GEA of $90.2 \%$ at 8 years after surgery. It should be noted here that to achieve a satisfactory patency and avoid competition of flow, the stenosis in the target vessel for GEA grafting needs to be at least $80 \%$. Other advantages of the GEA are its very low susceptibility to arteriosclerosis, ${ }^{26}$ its ability to improve flow in response to augmented myocardium demand, ${ }^{27}$ and its length being long enough to reach any coronary artery. ${ }^{28}$ Potential disadvantages of the use of the GEA are the increased risk of postoperative ileus and the risk of jeopardizing the graft in case a laparotomy is needed with time. $^{29}$

In the multivariable Cox regression analysis, age, obesity, smoking history, COPD, and CCSA class IV were the independent adverse predictors of long-term overall survival. Adverse predictors of long-term freedom from MACE were age and CCSA class IV. Studies that examined the influence of obesity, smoking (previous or current), and COPD on both early (in-hospital) and late (after discharge) survival after CABG have shown that all these 3 factors were associated with late, but not with early, mortality. ${ }^{30-32}$ It can be hypothesized that the impaired long-term survival in patients undergoing $\mathrm{CABG}$ with obesity, a smoking history, or COPD is a function of their related progressive disorder rather than the CABG surgery in itself. In the present study, diabetes mellitus was not an adverse predictor of long-term survival or MACE. Among 
the primary barriers to the widespread use of BITA is the concern about an increased risk of deep sternal wound infection, especially in patients with diabetes. ${ }^{33}$ In a systematic review of studies comparing BITA with SITA grafting in patients with diabetes, it was found that this increased risk was limited to patients with a pedicled BITA harvesting approach. ${ }^{34}$ Patients who underwent skeletonized BITA harvesting had a similar risk of deep sternal wound infection compared with SITA grafting. Notably, in a large population of propensity-score matched patients with diabetes, Dorman and colleagues ${ }^{35}$ observed improved long-term survival with BITA grafting compared with SITA grafting without any increase in perioperative morbidity or mortality.

\section{Study Limitations}

The present study has several limitations. First, this was an observational study without a control group. Therefore, comparisons to BITA grafting supplemented with the radial artery or the SVG as a third conduit could only be undertaken by reviewing the literature. Second, at the time the patient cohort underwent operations, the surgical technique presented in this study was predominantly used in relatively young and healthy patients. This might have influenced the long-term outcomes of the study. Nowadays, the technique is performed also in more high-risk patients. Third, the study included no data on the angiographic quality of the grafts at follow-up. Although it was not the intent of the study to report on graft patency, the findings in patients who required $\mathrm{PCI}$ after surgery suggest that there are no functional differences between the use of the GEA compared with BITA.

\section{CONCLUSIONS}

According to the results of this study, the exclusive use of in situ BITA and GEA grafts in CABG provides outstanding 15- and 20-year patient survival and freedom from cardiac events in relatively young and healthy patients. Further studies are needed in older patients with more severe comorbidities. Nevertheless, the results from this study and similar studies with sufficient follow-up time suggest that cardiac surgeons should embrace the application of total arterial grafting to further reduce the risks of long-term cardiac events, especially during the second decade after CABG. After Lytle's statement in 1999 that " 2 internal thoracic artery grafts are better than 1, , we may nowadays postulate that in 3-vessel coronary artery disease 3 arterial grafts are better than 2 .

\section{Conflict of Interest Statement}

Authors have nothing to disclose with regard to commercial support.

\section{References}

1. Lytle BW, Blackstone EH, Loop FD, Houghtaling PL, Arnold JH, Akhrass R, et al. Two internal thoracic artery grafts are better than one. J Thorac Cardiovasc Surg. 1999;117:855-72.

2. Weiss AJ, Zhao S, Tian DH, Taggart DP, Yan TD. A meta-analysis comparing bilateral internal mammary artery with left internal mammary artery for coronary artery bypass grafting. Ann Cardiothorac Surg. 2013;2:390-400.

3. Takagi H, Goto SN, Watanabe T, Mizuno Y, Kawai N, Umemoto T. A meta-analysis of adjusted hazard ratios from 20 observational studies of bilateral versus single internal thoracic artery coronary artery bypass grafting. $J$ Thorac Cardiovasc Surg. 2014;148:1282-90.

4. Rankin JS, Tuttle RH, Wechsler AS, Teichmann TL, Glower DD, Califf RM. Techniques and benefits of multiple internal mammary artery bypass at 20 years of follow-up. Ann Thorac Surg. 2007;83:1008-14.

5. Grau JB, Ferrari G, Mak AW, Shaw RE, Brizzio ME, Mindich BP, et al. Propensity matched analysis of bilateral internal mammary artery versus single left internal mammary artery grafting at 17-year follow-up: validation of a contemporary surgical experience. Eur J Cardiothorac Surg. 2012;41:770-5.

6. Kurlansky PA, Traad EA, Dorman MJ, Galbut DL, Zucker M, Ebra G. Thirty-year follow-up defines survival benefit for second internal mammary artery in propensity-matched groups. Ann Thorac Surg. 2010;90:101-8.

7. Tatoulis J, Buxton BF, Fuller JA. The right internal thoracic artery: the forgotten conduit-5,766 patients and 991 angiograms. Ann Thorac Surg. 2011;92:9-15.

8. Yanagawa B, Verma S, Mazine A, Tam DY, Jüni P, Puskas JD, et al. Impact of total arterial revascularization on long term survival: a systematic review and meta-analysis of 130,305 patients. Int J Cardiol. 2017;233:29-36.

9. Gaudino M, Puskas JD, Di Franco A, Ohmes LB, Iannaccone M, Barbero U, et al. Three arterial grafts improve late survival: a meta-analysis of propensity-matched studies. Circulation. 2017;135:1036-44.

10. Grandjean JG, Voors AA, Boonstra PW, den Heyer P, Ebels T. Exclusive use of arterial grafts in coronary artery bypass operations for three-vessel disease: use of both thoracic arteries and the gastroepiploic artery in 256 consecutive patients. J Thorac Cardiovasc Surg. 1996;112:935-42.

11. Hirose H, Amano A, Takanashi S, Takahashi A. Coronary artery bypass grafting using the gastroepiploic artery in 1,000 patients. Ann Thorac Surg. 2002;73: 1371-9.

12. Tavilla G, Kappetein AP, Braun J, Gopie J, Tjien AT, Dion RA. Long-term follow-up of coronary artery bypass grafting in three-vessel disease using exclusively pedicled bilateral internal thoracic and right gastroepiploic arteries. Ann Thorac Surg. 2004;77:794-9.

13. Tavilla G, Jackimovicz J, Berreklouw E. Intraoperative blood flow measurement of the right gastroepiploic artery using pulsed Doppler echocardiography. Ann Thorac Surg. 1997;64:426-31.

14. Clark TG, Bradburn MJ, Love SB, Altman DG. Survival analysis part I: basic concepts and first analyses. Br J Cancer. 2003;89:232-8.

15. Putter H, Fiocco M, Geskus RB. Tutorial in biostatistics: competing risks and multistate models. Stat Med. 2007;26:2389-430.

16. Glineur D, D'hoore W, Price J, Dorméus S, de Kerchove L, Dion R, et al. Surviva benefit of multiple arterial grafting in a 25-year single-institutional experience: the importance of the third arterial graft. Eur J Cardiothorac Surg. 2012;42: 284-90.

17. Lytle BW, Blackstone EH, Sabik JF, Houghtaling P, Loop FD, Cosgrove DM. The effect of bilateral internal thoracic artery grafting on survival during 20 postoperative years. Ann Thorac Surg. 2004;78:2005-12.

18. Garatti A, Castelvecchio S, Canziani A, Corain L, Generali T, Mossuto E, et al, Long-term results of sequential vein coronary artery bypass grafting compared with totally arterial myocardial revascularization: a propensity score-matched follow-up study. Eur J Cardiothorac Surg. 2014;46:1006-13.

19. Suma H, Tanabe H, Takahashi A, Horii T, Isomura T, Hirose H, et al. Twenty years experience with the gastroepiploic artery graft for CABG. Circulation. 2007;116(11 Suppl):I188-91.

20. Shi WY, Tatoulis J, Newcomb AE, Rosalion A, Fuller JA, Buxton BF. Is a third arterial conduit necessary? Comparison of the radial artery and saphenous vein in patients receiving bilateral internal thoracic arteries for triple vessel coronary disease. Eur J Cardiothorac Surg. 2016;50:53-60.

21. Parsa CJ, Shaw LK, Rankin JS, Daneshmand MA, Gaca JG, Milano CA, et al. Twenty-five-year outcomes after multiple internal thoracic artery bypass. $J$ Thorac Cardiovasc Surg. 2013;145:970-5.

22. Fitzgibbon GM, Kafka HP, Leach AJ, Keon WJ, Hooper GD, Burton JR Coronary bypass graft fate and patient outcome: angiographic follow-up of 
5,065 grafts related to survival and reoperation in 1,388 patients during 25 years. J Am Coll Cardiol. 1996;28:616-26.

23. Lüscher TF, Diederich D, Siebenmann R, Lehmann K, Stulz P, von Segesser L, et al. Difference between endothelium-dependent relaxation in arterial and in venous coronary bypass grafts. $N$ Engl J Med. 1988;319:462-7.

24. Dimitrova KR, Hoffman DM, Geller CM, Dincheva G, Ko W, Tranbaugh RF. Arterial grafts protect the native coronary vessels from atherosclerotic disease progression. Ann Thorac Surg. 2012;94:475-81

25. Suzuki T, Asai $T$, Nota H, Kuroyanagi S, Kinoshita T, Takashima N, et al. Early and long-term patency of in situ skeletonized gastroepiploic artery after off-pump coronary artery bypass graft surgery. Ann Thorac Surg. 2013;96:90-5.

26. Larsen E, Johansen A, Andersen D. Gastric arteriosclerosis in elderly people. Scand J Gastroenterol. 1969;4:387-9.

27. Tavilla G, Pijls NH, Peels KH, Berreklouw E. Noninvasive assessment of coronary flow reserve in the right gastroepiploic artery graft. Ann Thorac Surg. 2000;70:2040-4

28. Tavilla G, van Son JA, Verhagen AF, Smedts F. Retrogastric versus antegastric routing and histology of the right gastroepiploic artery. Ann Thorac Surg. 1992;53:1057-61.

29. Yano K, Tsubota H, Arai Y, Abe T, Hanyu M. Abdominal surgery for gastric cancer following coronary artery bypass grafting using an in situ right gastroepiploic artery graft. J Card Surg. 2017;32:538-41.
30. Benedetto U, Danese C, Codispoti M. Obesity paradox in coronary artery bypass grafting: myth or reality? J Thorac Cardiovasc Surg. 2014;147:1517-23.

31. Saxena A, Shan L, Reid C, Dinh DT, Smith JA, Shardey GC, et al. Impact of smoking status on early and late outcomes after isolated coronary artery bypass graft surgery. J Cardiol. 2013;61:336-41.

32. Angouras DC, Anagnostopoulos CE, Chamogeorgakis TP, Rokkas CK, Swistel DG, Connery CP, et al. Postoperative and long-term outcome of patients with chronic obstructive pulmonary disease undergoing coronary artery bypass grafting. Ann Thorac Surg. 2010;89:1112-8.

33. Savage EB, Grab JD, O’Brien SM, Ali A, Okum EJ, Perez-Tamayo RA, et al. Use of both internal thoracic arteries in diabetic patients increases deep sternal wound infection. Ann Thorac Surg. 2007;83:1002-6.

34. Deo SV, Shah IK, Dunlay SM, Erwin PJ, Locker C, Altarabsheh SE, et al. Bilateral internal thoracic artery harvest and deep sternal wound infection in diabetic patients. Ann Thorac Surg. 2013;95:862-9.

35. Dorman MJ, Kurlansky PA, Traad EA, Galbut DL, Zucker M, Ebra G. Bilateral internal mammary artery grafting enhances survival in diabetic patients: a 30-year follow-up of propensity score-matched cohorts. Circulation. 2012;126:2935-42.

Key Words: coronary artery bypass grafting, total arterial revascularization, right gastroepiploic artery, follow-up studies 